\title{
Can molecular cell biology explain chromosome motions?
}

Daniel H Shain ${ }^{1 *}$ and L John Gagliardi ${ }^{2}$

* Correspondence:

dshain@camden.rutgers.edu

${ }^{1}$ Department of Biology, Rutgers

The State University of New Jersey,

315 Penn St., Camden, NJ 08102,

USA

Full list of author information is available at the end of the article

\section{() Biomed Central}

\begin{abstract}
Background: Mitotic chromosome motions have recently been correlated with electrostatic forces, but a lingering "molecular cell biology" paradigm persists, proposing binding and release proteins or molecular geometries for force generation.
\end{abstract}

Results: Pole-facing kinetochore plates manifest positive charges and interact with negatively charged microtubule ends providing the motive force for poleward chromosome motions by classical electrostatics. This conceptual scheme explains dynamic tracking/coupling of kinetochores to microtubules and the simultaneous depolymerization of kinetochore microtubules as poleward force is generated.

Conclusion: We question here why cells would prefer complex molecular mechanisms to move chromosomes when direct electrostatic interactions between known bound charge distributions can accomplish the same task much more simply.

\section{Introduction}

Molecular mechanisms underlying mitosis, particularly those associated with directed chromosome movement during the cell cycle, have been pursued intensely over the past two decades with no clear picture emerging-or is there? Recent experiments identify positively charged kinetochore-associated molecules (e.g., Ndc80/Hec1) that likely interact with negatively charged microtubule ends to generate electrostatic-dependent poleward forces that drive chromosome motion [1,2]. This concept diverges from the conventional "molecular cell biology" paradigm, but does not stray far from molecularbased approaches that require specific binding proteins or molecular geometries for force generation. In fact, considerable time and resources are being invested pursuing molecular machinery that may not exist.

\section{Discussion}

Indeed, current thought on mitotic motions is shifting from a molecular to a more electrostatics-based framework [1-3], and perhaps not too surprisingly in light of theoretical predictions made almost a decade ago, which have gone mostly unrecognized [4-6]. Specifically, pole-facing kinetochore plates manifest positive charges and interact with negatively charged microtubule ends providing the motive force for poleward chromosome motions (Figure 1). This conceptual scheme explains dynamic tracking/ coupling of kinetochores to microtubules and the simultaneous depolymerization of kinetochore microtubules as poleward force is generated. Charges, of course, are on

(c) 2011 Shain and Gagliardi; licensee BioMed Central Ltd. This is an Open Access article distributed under the terms of the Creative Commons Attribution License (http://creativecommons.org/licenses/by/2.0), which permits unrestricted use, distribution, and reproduction in any medium, provided the original work is properly cited. 


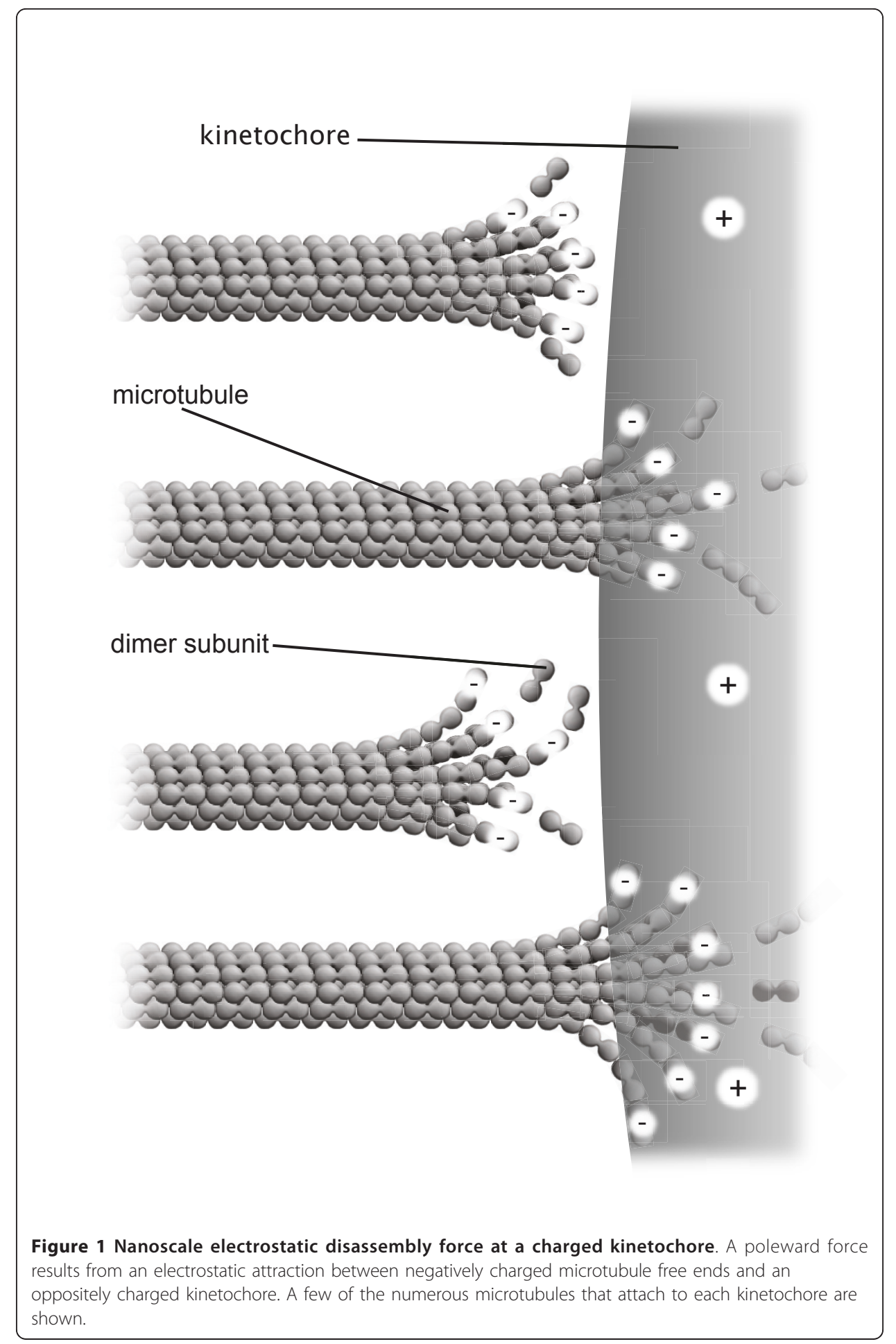

the molecules (i.e., microtubules, kinetochore binding proteins), but the molecules are mere carriers of charges that cause chromosome motions by classical electrostatics. Note that antipoleward chromosome motions are also integrated into the complex motions of mitosis [4-6]. Collectively, this concept is very different from the electrostatics-based, molecular binding and release mechanisms presently suggested-but not 
elucidated-in recent literature [1,2]. For example, a lock and key mechanism involving the calponin homology domain, which has recently been associated with kinetochore attachments to microtubule ends [7,8], does not explain complex chromosome motions during prometaphase, metaphase and anaphase. Alternatively, we suggest that calponin may serve to position and stabilize the microtubule-kinetochore end-on attachment, while the highly positive, unstructured tail of $\mathrm{Ndc} 80 / \mathrm{Hec} 1$ is likely the dynamic electrostatic link with microtubule ends.

Perhaps the most surprising part of this story is the untimely resistance to classical electrostatics by the cell biology community. For example, critiques including "... groundless speculations in which the authors $[s i c]$ attempted to explain chromosome motions by nanoscale electrostatics and unnecessary sophistry..." [9], and requiring "... hypothetical long-range electrostatic forces..." [10] suggest an inherent bias againstand general unawareness of-electrostatic forces and their fundamental role in cellular processes. In response, nanoscale electrostatics has in fact emerged as a primary focus for chromosome movements [1,2], and is far from hypothetical in light of water layering [11] and reduction of the dielectric constant between charged protein surfaces [12].

To gain perspective on this subject, it may be instructive to consider the problem of cell division in an evolutionary context, and more specifically in an ancestral cell that lacked "modern" molecular machinery. Clearly, cells have been dividing since the origin of life, and the mechanisms underlying this fundamental process in modern cells are likely derived from some ancestral state-just like other cellular processes (e.g., translation, splicing) were likely derived from ancestral, catalytic RNAs that were later supplemented with supporting proteins. In a simple cell, all chromosome movements during mitosis are readily explained by electrostatic interactions between core components of the system (i.e., charged DNA, microtubules), without the requirement for supplemental protein machinery [4-6]. Why then should modern cells be expected to conduct mitosis in a fundamentally different way (i.e., the molecular cell biology paradigm)? Rather, a more parsimonious view might consider mitosis as an emergent property, with specialized DNA and microtubules as key players and electrostatics as the driving force. Analogous with other cellular processes, supplemental protein machinery likely arrived later to increase efficiency in an increasingly complex cellular environment.

Our current bottleneck in understanding mitotic chromosome movements seems reminiscent of another challenging question in our imperfect scientific history, namely the self-imposed constraints of ancient Greek astronomers in trying to explain geocentric planetary motions with perfect circles. Indeed, layers of epicycles were incorporated into an increasingly complex scheme of integrated circles that was "understood" by only the best natural philosophers of the time. It took $\sim 2,000$ years of scientific work by Brahe, Galileo, Kepler and Newton to achieve the simplicity of a modern theory based on a different conceptual scheme, i.e., elliptical orbits in a heliocentric solar system.

\section{Conclusions}

Twenty years ago, Guenter Albrecht-Buehler lamented the view of many cell biologists that "molecular analysis of cellular functions" is the only acceptable approach to cell biology [13], yet this precarious ideology seems even more entrenched in current cell 
science. Imposing molecular approaches (e.g., binding and release mechanisms) at the outset does not preserve scientific open-mindedness in solving nature's riddles. Although much good science has been done in molecular biology, do we really want modern cell biologists spiraling around epicycles like ancient Greek astronomers? Instead, perhaps we should ask why cells would prefer complex molecular mechanisms to move chromosomes when direct electrostatic interactions between known bound charge distributions can accomplish the same task much more simply.

Author details

'Department of Biology, Rutgers The State University of New Jersey, 315 Penn St., Camden, NJ 08102, USA. ${ }^{2}$ Department of Physics, Rutgers The State University of New Jersey, 315 Penn St., Camden, NJ 08102, USA.

\section{Authors' contributions}

DHS made intellectual contributions and drafted the manuscript. LJG conceived the study. All authors read and approved the final manuscript.

\section{Competing interests}

The authors declare that they have no competing interests.

Received: 3 March 2011 Accepted: 27 May 2011 Published: 27 May 2011

\section{References}

1. Guimaraes GJ, Dong Y, McEwen B, DeLuca JG: Kinetochore-microtubule attachment relies on the disordered Nterminal tail domain of Hec1. Current Biol 2008, 18:1778-1784.

2. Miller SA, Johnson ML, Stukenberg PT: Kinetochore attachments require an interaction between unstructured tails on microtubules and $\mathrm{Ndc} 80^{\mathrm{Hec} 1}$. Current Biol 2008, 18:1785-1791.

3. Liu J, Onuchic JN: A driving and coupling "Pac-Man" mechanism for chromosome poleward translocation in anaphase A. Proc Natl. Acad Sci. USA 2006, 103:18432-18437.

4. Gagliardi L: Electrostatic force in prometaphase, metaphase, and anaphase-A chromosome motions. Phys. Rev. E 2002, 66:011901-1-011901-8.

5. Gagliardi L: Electrostatic Considerations in Mitosis iUniverse Publishing, Bloomington, IN; 2009.

6. Gagliardi L: Electrostatic force generation in chromosome motions during mitosis. J. Electrostat 2005, 63:309-327.

7. Maure JF, Komoto S, Oku Y, Mino A, Pasqualato S, Natsume K, Clayton L, Musacchio A, Tanaka TU: The Ndc80 loop region facilitates formation of kinetochore attachment to the dynamic microtubule plus end. Current Biol. 2011, 21:207-213.

8. Hsu KS, Toda T: Ndc80 internal loop interacts with Dis1/TOG to ensure proper kinetochore-spindle attachment in fission yeast. Current Biol 2011, 21:214-220.

9. Mogliner A, Wollman R, Civelekoglu-Scholey G, Scholey J: Modeling mitosis. Trends Cell Biol 2006, 16:88-96.

10. Joglekar AP, Bloom KS, Salmon ED: Mechanisms of force generation by end-on kinetochore attachments. Current Opin. Cell Biol 2010, 22:57-67.

11. Pauling L: The adsorption of water by proteins. J. Am. Chem. Soc 1945, 67:555.

12. Bockris JO, Reddy AKN: Modern Electrochemistry New York: Plenum Press; 1977.

13. Albrecht-Buehler G: In defense of non-molecular biology. Int. Rev. Cytol 1990, 120:191-241.

doi:10.1186/1742-4682-8-15

Cite this article as: Shain and Gagliardi: Can molecular cell biology explain chromosome motions? Theoretical Biology and Medical Modelling 2011 8:15.

\section{Submit your next manuscript to BioMed Central and take full advantage of:}

- Convenient online submission

- Thorough peer review

- No space constraints or color figure charges

- Immediate publication on acceptance

- Inclusion in PubMed, CAS, Scopus and Google Scholar

- Research which is freely available for redistribution 